\title{
FONTES FRANCISCANAS: HISTORIOGRAFIA CLÁSSICA DA ORDEM NO BRASIL COLONIAL
}

Tania Conceição Iglesias ${ }^{1}$

taniglesias@yahoo.com.br

\section{RESUMO:}

Artigo de divulgação das fontes documentais bibliográficas que abordam a ação missionária da Ordem Franciscana no Brasil Colonial (1500-1822), decorrente de investigações desenvolvidas entre 2005 a 2010. Este texto, primeiro, de um projeto de três publicações sobre o assunto, apresenta a historiografia clássica da Ordem Franciscana no Brasil Colonial e oferece uma pequena resenha da fonte documental "Novo Orbe Seráfico Brasílico" ou "Crônica dos Frades Menores do Brasil", escrita entre 1752-1761 por Antonio de Santa Maria Jaboatão (1695-1779).

Palavras-chave: Fontes Documentais, Brasil, Educação Colonial, Franciscanos, Historiografia.

\section{FRANCISCAN SOURCES: CLASSICAL HISTORIOGRAPHY OF COLONIAL ORDER IN BRAZIL}

\begin{abstract}
:
This article talks about the divulgation of bibliographical and documentary sources that refer to the missionary action of the franciscan Order in Colonial Brazil (1500 - 1822), resulting from the investigations which were developed between 2005 to 2010. This text is the first of a series of the three publications about the franciscan sources, and it presents the classical historiography of the Franciscan Order in colonial Brazil. Besides that, it also offers a short review of the documentary source: "Novo Orbe Seráfico Brasílico" or "Chronical of Friars Minor from Brazil”, written by Jaboatão (1695-1779).

Keywords: Documentary Sources, Brazil, Colonial Education, Franciscan Historiography
\end{abstract}

Este artigo de divulgação faz parte do projeto de publicação das fontes documentais e bibliográficas que abordam a ação missionária referente à Ordem Franciscana no Brasil Colonial (1500-1822). O trabalho é decorrente de investigações desenvolvidas entre 2005 a $2010^{2}$. Na inquirição realizada no longo período localizado entre 1500 a 2010, encontrouse apenas 32 produções, cuja temática permite qualificar como fontes documentais e bibliográficas ou secundárias sobre o tema. Do levantamento, onde foram considerados livros, artigos, teses e dissertações, 22 produções classificam-se como Historiografia dos Franciscanos no Brasil, escrita ordinariamente pelos membros da Ordem; seis produções como Historiografia Brasileira, escrita por autores que abordaram o tema em relação à história do Brasil e, quatro produções como Historiografia da Educação Brasileira. Estes números simbolizam o "Estado da Arte" sobre a ação missionária franciscana no Brasil, representando a irrisória atenção oferecida ao assunto, em relação aos quinhentos e dez anos de presença da Ordem no Brasil. Além disso, demonstram, tendo em conta a análise da participação ativa dos frades no campo evangelizador e educativo brasileiro ${ }^{3}$, uma importante lacuna histórica deixada pelos historiógrafos e pesquisadores em relação ao tratamento oferecido à questão. 
Com a intenção de contribuir, por meio da divulgação desses trabalhos, para minimizar o desconhecimento do assunto nos meios acadêmicos, bem como acrescentar este estudo à tênue produção existente, pretende-se publicar três artigos que em seu conjunto formarão a revisão completa dos estudos desenvolvidos. O presente texto é o primeiro deles e tem o objetivo de apresentar a Historiografia clássica dos Franciscanos no Brasil Colonial e oferecer uma pequena resenha da fonte documental "Novo Orbe Seráfico Brasílico" ou "Crônica dos Frades Menores do Brasil, principal produção bibliográfica e referência obrigatória sobre a Ordem Franciscana do Período Colonial.

A divisão do projeto em três artigos separados se justifica pelo fato de que, não obstante a pouca quantidade de trabalhos publicados sobre o tema e, notadamente, devido ao mesmo fenômeno, o volume de informações produzidas sobre os mesmos contrastou com o pouco número de obras. Por se tratar de produções raramente conhecidas no meio acadêmico, foi preciso, na medida do possível, desenvolver um pequeno estudo sobre a vida e a obra dos autores que é oferecido em notas explicativas. Essas informações, embora imprescindíveis, avolumou o trabalho, determinando, por essa razão, a sua divisão para a divulgação. Embora se trate do mesmo objeto apresentado em três momentos diversos, não houve parcelamento do conteúdo e nem prejuízo à visão de totalidade, pois, os artigos apresentam classificações e períodos distintos. Importante salientar que devido aos escassos estudos sobre a historiografia franciscana, quase não há referência bibliográfica sobre a biografia dos autores. Muitas informações foram coletadas mediante solicitação direta aos membros da Ordem.

Desta forma, para sistematizar e viabilizar a publicação da pesquisa, o trabalho foi dividido em três artigos. O primeiro, e presente artigo, intitulado "Fontes Franciscanas: Historiografia Clássica da Ordem no Brasil Colonial” abordará as Crônicas e obras de historiadores franciscanos que, por seu valor histórico, constituem-se fontes documentais, destacando uma pequena resenha da Principal fonte histórica franciscana no Brasil Colonial. O segundo artigo se intitulará: "Fontes Franciscanas: Historiografia franciscana Brasileira”, abordará as produções específicas da historiografia franciscana respeitando a ordem cronológica em que foram produzidas; o terceiro e último artigo do conjunto, que se intitulará: "Fontes Franciscanas: Os Franciscanos na historiografia do Brasil e na História da Educação Brasileira" abordará as obras clássicas de história do Brasil Colonial que fazem referência à presença missionária dos franciscanos no tempo e espaço destacado, bem como, trabalhos que investigaram a ação catequética educacional dos franciscanos durante esse período.

\section{FONTES DOCUMENTAIS FRANCISCANAS NO BRASIL COLONIAL}

A obra "Narrativa da Custódia de Santo Antonio do Brasil: 1584-1621", de Frei Manuel da Ilha (?-1637), é a mais antiga crônica sistematizada sobre os Franciscanos no Brasil. Finalizada em 1621, a Narrativa de Frei Manuel da Ilha foi traduzida do latim para o português, mais de três séculos depois por Frei Ildefonso Silveira (1922-2002) ${ }^{4}$, apresenta texto bilíngüe e foi publicada pela Editora Vozes, em 1975.

Frei Manuel da Ilha, incumbido pelo Superior Geral da Ordem de escrever a narrativa, foi membro da Província Franciscana de Santo Antonio de Portugal, conselheiro e guardião do Convento de Lisboa. Não foi possível encontrar a data de seu nascimento, mas, há registros na literatura consultada sobre seu falecimento em 1637. Pelo fato de nunca ter vindo ao Brasil e por ter escrito a obra baseado em fontes como relações e memórias de confrades pertencentes à Custódia franciscana brasileira, possui imprecisões 
que são apontadas na introdução pelo tradutor Frei Ildefonso Silveira que, inclusive, levanta a hipótese de o autor ter se servido de uma Crônica sobre a Custódia do Brasil que teria sido escrita por Frei Vicente do Salvador, cujo paradeiro se desconhece, mas é citada pelos historiadores mais antigos da Ordem. O suposto trabalho teria sido escrito e levado a Portugal por frei Vicente do Salvador por ocasião de sua viagem ao Reino, por volta de 1618-619.

Embora a obra trate da Custódia de Santo Antonio do Brasil, que se estendia da Paraíba ao Rio de Janeiro, no período de 1585-1621, seus nove conventos, as missões mais importantes entre os índios daquela região, os necrológios de alguns missionários, a lista dos custódios e a questão surgida entre os jesuítas e franciscanos no início da catequese na Paraíba ${ }^{5}$, refere-se, também, a missionários franciscanos anteriores ${ }^{6}$, bem como ao relato do início da Missão franciscana na Amazônia. Essa missão foi empreendida pela Província Portuguesa de Santo Antonio de Portugal em 1617 que, depois, se tornou uma Custódia separada da de Olinda, constituindo-se, dessa forma, em preciosa fonte documental para a pesquisa do Brasil quinhentista.

Apesar do estilo apologético do texto de frei Manuel da Ilha, ele consegue propiciar ao leitor a compreensão de importantes questões, tais como: as barreiras iniciais que a Província franciscana portuguesa impôs à fundação da primeira Custódia franciscana brasileira, especialmente em relação à concessão de missionários em 1589; o relato sobre a obra missionária de Frei Pedro Palácios ${ }^{7}$; e as controvérsias entre jesuítas e franciscanos nas Missões da Paraíba. Para Frei Ildefonso, são essas duas últimas as contribuições mais importantes da obra por se tratar de narrativas baseadas em documentos autênticos, como sumários e vários atos governamentais, bem como testemunhas oculares que missionaram na Província.

Entre essas testemunhas oculares, destaca-se Frei Vicente do Salvador (1564-1639), que será incluído nessa parte da revisão bibliográfica, dedicada aos cronistas da Ordem. Essa ênfase se deve menos por ser considerado como o primeiro escritor da "História do Brasil", obra datada de 1627, pela qual tem sido lembrado, mas, principalmente, pelo importante debate suscitado entre os historiadores sobre sua "Crônica da Custódia do Brasil", obra desaparecida, de 1618 e, portanto, precedente à sua História do Brasil.

O principal debate sobre a obra não incide sobre sua existência, já que são vários os cronistas e historiadores seiscentistas que a citam. O debate centra-se na questão de ter sido essa um trabalho singular, ou uma parte da História do Brasil, obra que permaneceu inédita por mais de dois séculos, quando foi encontrada e publicada integralmente pela primeira vez em 1888, nos Anais da Biblioteca Nacional, com um estudo inicial de Capistrano de Abreu, o mesmo historiador que se incumbiu da preparação e da edição definitiva de 1918.

Independentemente do debate sobre a primazia das ordens religiosas no trabalho catequético no Brasil Colonial, questão esta tão cara aos historiadores da Ordem franciscana, os escritos de Frei Vicente do Salvador constituem elemento fundamental para a historiografia, sobretudo por se tratar de um autor de nacionalidade brasileira ${ }^{8}$.

$\mathrm{Na}$ bibliografia franciscana brasileira consultada, as obras de frei Vicente são fartamente exploradas, notadamente nos trabalhos sobre a história da Província de Santo Antonio do Brasil. Destaca-se, ainda, o trabalho de Dom Adriano Hypólito (1918-1996) ${ }^{9}$ publicado no volume I da edição comemorativa do tricentenário da Província Franciscana no Brasil, publicada em Pernambuco em 1957 e em que o autor toma a matéria para análise. No trabalho intitulado "Frei Vicente do Salvador e sua Crônica da Custódia do Brasil”, Frei Adriano analisa o assunto a partir da seguinte questão: Frei Vicente escreveu duas obras - "A Crônica da Custódia do Brasil" e a "História do Brasil" - ou somente 
uma que era mencionada com dois nomes distintos?

$\mathrm{Na}$ historiografia brasileira, há autores, como Varnhagen, que supõem tratar-se de uma só obra e há aqueles, como Capistrano de Abreu, que afirmam tratar-se de duas obras diferentes. Este último, profundo conhecedor do trabalho do cronista quinhentista, admite que foram aproveitados conteúdos da Crônica na escrita de A História do Brasil, mas assegura a existência de ambas.

Através de investigação da historiografia Colonial e dos cronistas da Ordem franciscana, como Frei Antonio de Santa Maria Jaboatão, Frei Adriano analisou a existência da obra, concluindo, por meio dessas fontes, que Frei Vicente do Salvador produziu duas obras, sendo que a primeira foi utilizada por muitos autores sem a devida referência. Frei Adriano levanta, inclusive, a seguinte questão: a obra de Frei Manuel da Ilha, devido, entre outros argumentos, ao detalhamento de fatos que só poderiam ser descritos por uma testemunha ocular, e por isso mesmo impossível ao autor que nunca veio ao Brasil, não teria sido a simples tradução da "Crônica da Custódia do Brasil" de Frei Vicente?

Nesse caso, a Crônica de Frei Vicente, de 1618, constituir-se-ia na primeira obra historiográfica da Ordem Franciscana no Brasil. Entretanto, não é na anterioridade ou não dessa obra que se encontra sua relevância, mas, nas valiosas informações que a transformou em importante fonte documental citada em obras clássicas da Ordem que ajudam a dimensionar a Missão franciscana no Período Colonial brasileiro.

No mesmo período, encontra-se a obra do frade Capuchinho francês, Claude d'Abbeville, intitulada "História da Missão dos Padres Capuchinhos na Ilha do Maranhão e suas Circunvizinhanças", escrita em 1614, traduzida pela primeira vez no Brasil por César Augusto Marques ${ }^{10}$ em 1874 e reimpressa em 2002 pela Editora Siciliano. Além dessa, existem outras traduções e publicações das quais se destaca a de Capistrano de Abreu (1922) que também prefacia esta edição da obra de Frei Claude" . "História da Missão Capuchinha na Ilha do Maranhão e Circunvizinhança" é uma crônica que relata pormenorizadamente a viagem e a experiência do Frei no Brasil. Capistrano de Abreu destaca na obra a importante contribuição etnográfica e lingüística que possui e as informações descritas sobre a vida e os costumes dos índios do Maranhão.

Outra importante narrativa contemporânea à de Frei Claude foi escrita por Frei Yves d'Evreux (1570-1620) ${ }^{12}$ intitulada "Viagem ao norte do Brasil" 13, publicada em 1615. ${ }^{14}$ A obra não trata unicamente da história da Missão dos Capuchinhos franceses no Maranhão, mas, dedica um capítulo com relevantes relatos a respeito da mesma.

Pode-se afirmar que as obras referidas são as mais genuínas fontes bibliográficas sobre os franciscanos no Período Colonial, citadas abundantemente pela historiografia franciscana desde as Crônicas até as obras de cunho científico. Entretanto, são identificados como trabalhos bibliográficos mais sistematizados sobre a história dos franciscanos no Brasil Colonial os trabalhos escritos pelos Cronistas Oficiais da Ordem: Frei Antonio de Santa Maria Jaboatão (1695-1779) e Frei Apolinário da Conceição (16921760) $)^{15}$.

A produção bibliográfica de Frei Apolinário da Conceição é ampla. Escreveu várias obras sobre os franciscanos, mas nem todas foram publicadas e muitas se perderam. Tratase de crônicas, biografias e livros com apontamentos sobre a Ordem. Entre as obras publicadas, se encontram "Primazia Seráfica na Região da América, Lisboa", 1732; "Pequenos na Terra e Grandes no Céu”, 5 volumes. Lisboa, 1732-1754; "Claustro Franciscano”, Lisboa, 1740; “Eco Sonoro: Biografia de Frei Fabiano de Cristo”, Lisboa, 1748, reeditado pela Editora Vozes, Petrópolis, em 1929, e "Epítome da Província Franciscana da Imaculada Conceição no Brasil", composta em Lisboa em 1730, cujo 
manuscrito original se localiza na Biblioteca Nacional do Rio de Janeiro. Publicada com introdução e notas de Frei Gentil Titton, na Revista do Instituto Histórico Geográfico brasileiro, volume 296, de julho e setembro de 1972, tal obra será destacada, devido tanto à precedência cronológica que se está priorizando nesta revisão bibliográfica, quanto por se tratar de obra específica sobre a Província franciscana brasileira.

Frei Titton argumenta que Frei Apolinário, devido à sua pouca instrução, não foi um escritor original, foi mais um compilador. Sua obra não possui um estilo particular e os textos não revisados possuem vários erros ortográficos. O manuscrito original de "Epítome da Província Franciscana da Imaculada Conceição no Brasil", precisou de várias correções. Isso é explicitado por Frei Titton na introdução à publicação feita na Revista do Instituto Histórico Geográfico brasileiro, em 1972.

O manuscrito produzido em Lisboa é compilação de documentos e informações referentes à Província da Imaculada Conceição do Rio de Janeiro, suas Missões e seus Conventos. Entretanto, os capítulos iniciais referem-se aos antecedentes históricos da Ordem no Brasil, destacando-se o capítulo que aborda a primazia da Ordem Franciscana no Brasil, no qual o autor enfatiza a precedência missionária dessa Ordem em terras brasileiras ${ }^{16}$. Os demais capítulos são compostos pela descrição sistemática da fundação e pelo desenvolvimento da Província da Imaculada Conceição, seus Conventos, Hospícios, cidades onde foram fundadas as Igrejas e os frades que neles viveram e morreram.

Importante salientar que, na maior parte da literatura sobre os franciscanos no Brasil, tanto a antiga como a atual, seja ela constituída de crônicas ou trabalhos de cunho científico, percebe-se uma insatisfação em relação à historiografia brasileira. A insistente ênfase na precedência da Ordem na evangelização do país, deixa transparecer a existência de problemas relativos à resistência na aceitação da legitimidade da anterioridade da Ordem em relação a outras na tarefa missionária no Brasil. Frei Apolinário, em "Primazia Seráfica na Região da América", faz dessa questão o núcleo do seu trabalho. Ele assevera que seu objetivo é mostrar a primazia da Ordem franciscana na conversão da América.

Essa preocupação é a mesma manifestada na obra Clássica da Ordem, que pelo seu valor documental, será aqui apresentada em forma de resenha.

\section{RESENHA}

JABOATÃO, Antonio de Santa Maria. Novo Orbe Seráfico Brasílico ou Crônica dos Frades Menores do Brasil. Escrita entre 1752-1761.

Jaboatão está para Ordem franciscana no Brasil Colonial, (com a ressalva de que ele vivenciou grande parte do que escreveu) assim como Serafim Leite, para a Companhia de Jesus por ter narrado a crônica da Companhia desde a instalação dos primeiros jesuítas nos primórdios da colonização. Porém, Serafim Leite se baseou em vasta documentação dos arquivos da Companhia, já em 1936.

Frei Antonio de Santa Maria Jaboatão, cronista, historiador e poeta, nasceu em Sant'Ana do Jaboatão, Pernambuco, em 1695. Ingressou na ordem franciscana em 1716, professando em 1717. Iniciou seus estudos no Convento de Santo Antonio do Paraguaçu na Bahia, concluindo-os em 1725, quando voltou a Recife.

Sua primeira aspiração foi ser poeta, mas destacou-se como pregador, cronista, genealogista e tornou-se membro da Academia Brasílica dos Renascidos. Exerceu diversos cargos na ordem e, em 1755, foi nomeado cronista da Província Franciscana de Santo Antonio do Brasil. Produziu ativamente até a sua morte na Bahia em 1779. O nome do Frei franciscano apresenta grafias diferentes. Encontram-se as seguintes formas na citação de 
seu sobrenome: Jabuatão, Jaboatão e Jaboatam. Nesse trabalho, em decorrência de ser essa, a mais corrente na historiografia franciscana, será empregada a grafia Jaboatão.

Frei Jaboatão publicou várias obras e sermões. Entre elas destacam-se: Discurso histórico, geographico, genealógico, político e encomiástico, recitado em a nova celebridade, que dedicaram os pardos de Pernambuco ao santo da sua cor, o Beato Gonçalo Garcia (Lisboa, 1751); Sermão de Santo Antonio, em O dia do Corpo de Deus (Lisboa, 1751); Sermão de S. Pedro Martyr, pregado na matriz do Corpo Santo do Reciffe (Lisboa, 1751); Josephina Regio equivoco-panegyrica, tres praticas e um sermão do glorioso Patriarcha S. José, offerecidos ao Serenissimo Rei D. José I, pregados na Igreja matriz da Paraiba (Lisboa, 1753); Gemidos seráficos. Exéquias celebradas pela Província de Santo António na morte do fidelíssimo rei D. João V (Lisboa, 1755); Jaboatão Mystico, em correntes sacras, dividida em: corrente primeira, panegyrica e moral (Lisboa, 1758), todavia, sua mais importante obra, pela qual ficou conhecido e reconhecido como uma clássico da literatura franciscana brasileira é, em sua grafia do original manuscrito, intitulado : Orbe Serafico Novo Brazilico descoberto, estabelecido e cultivado a influxos da nova luz de Italia, estreita brilhante de Hespanha, luzido sol de Padua, astro do céo de Francisco, o thaumaturgo portuguez Santo Antonio, a quem vae consagrado como theatro glorioso e parte primeira da chronica dos Frades menores da mais estreita e regular observancia da Provincia do Brazil, impresso em Lisboa em 1761, com o título: Novo Orbe serafico brazilico, ou Chronica dos frades menores da provincia do Brazil.

Em 1858, por ordem do Instituto Historico e Geographico Brazileiro, a obra foi reimpressa no Rio de Janeiro em dois volumes. Em 1859, por ordem do mesmo instituto iniciou-se a publicação da segunda parte inédita da obra com o título: Novo Orbe serafico brasílico ou Chronica dos frades menores, Parte segunda (inédita), Rio de Janeiro, v. I em 1859, ao qual seguiram a publicação de outros dois volumes, o v. II, em 1861 e o v. III, em 1862.

Em 1979, por sugestão de José Antônio Gonsalves de Melo Neto ${ }^{17}$, então presidente do Instituto Arqueológico, Histórico e Geográfico de Pernambuco, a Assembléia Legislativa de Recife reeditou o primeiro volume da primeira parte da obra que é uma edição fac-símile da edição de 1761, acrescida do prefácio preparado por José Antônio Gonsalves de Melo Neto.

Em 1980, em comemoração ao bicentenário da morte do autor e dando prosseguimento ao projeto, a Assembléia Legislativa de Pernambuco, reeditou o segundo volume da primeira parte, bem como a segunda parte da obra Novo Orbe Seráfico Brasílico ou Crhonica dos Frades Menores da Província do Brasil, contendo os três volumes fac-similes das edições de 1859, 1861 e 1862, com nota Prévia de Antonio Carlos de Oliveira, então, presidente da Assembléia Legislativa de Pernambuco.

A edição que se resenha nesta ocasião, é a de 1979 e as de 1980, nas quais estão contidos os cinco volumes que compõem a obra em sua totalidade. A princípio, aos pouco familiarizados, a sua organização é um pouco complexa. Por essa razão, é preciso se deter na explicação da mesma.

Os cinco volumes estão divididos em duas partes. A parte primeira é composta de dois volumes, publicados separadamente. A parte segunda é composta de três volumes publicados em uma mesma encadernação, totalizando, dessa forma, um conjunto de três livros onde se concentram os cinco volumes.

O primeiro volume da primeira parte apresenta preâmbulo ou introdução, seis 'digresam' ou digressões divididas em estâncias ou capítulos e, índex ou índice geral divididos em 414 páginas. Neste volume o autor fala da chegada dos europeus e da organização da Ordem franciscana e as primeiras povoações litorâneas, deixando registradas biografias, e obras 
escritas pelos frades franciscanos, bem como, a descrição de tribos indígenas, das capitanias, da administração da Ordem, da origem de vilas, de personalidades políticas da época e prodígios da Ordem ou referentes ao campo espiritual naquele contexto. Em suas próprias palavras, discorre pelas várias nações de gentios que habitavam as costas do Brasil, desde o Grão Pará até o Rio do Prata, os distritos a que pertenciam, seus nomes, seus costumes e, " gentilidades mais notáveis", enfocando, em todas elas, o trabalho da Ordem.

O segundo volume da primeira parte possui 422 páginas e é composto de 37 capítulos e um índice alfabético onde destaca os feitos notáveis que se encontram registrados na Crônica. De acordo com o autor, este volume teve objetivo de mostrar como o Brasil foi descoberto, cultivado e estabelecido por religiosos menores, sendo neles os primeiros. Apresenta seus progressos espirituais desde o ano de 1500 até 1585, quando foi fundada a primeira custódia franciscana em Olinda. Suas missões, algumas biografias de membros ilustres e outros acontecimentos daquele contexto e de contextos mais próximos ao autor.

$\mathrm{Na}$ segunda parte da obra, apresentam-se encadernados seus três últimos volumes precedidos de uma "advertência", quando o autor faz complementação ao título; nove "aditamentos" que tratam da correção ou adições de informações complementares aos conteúdos publicados e uma "protestação" ou protesto, provavelmente sobre alguma crítica à Igreja a qual ele defende e, por fim, renova sua obediência à Instituição.

Os três volumes da segunda parte são divididos por livros numerados em ordem contínua. No volume I consta o livro primeiro e segundo; no volume II, consta o livro terceiro, quarto e quinto; e o volume III, consta o livro sexto e sétimo. Nesta segunda parte da obra, o autor trabalha com temas mais específicos. No primeiro volume o autor disserta sobre a história do Convento de São Francisco da Bahia e da ação da Ordem. No segundo volume aborda os fatos históricos e as fundações dos Conventos franciscanos no Brasil e no terceiro e último volume, dedica-se a escrever sobre a Ordem segunda, de Santa Clara onde destaca a fundação e desenvolvimento do Convento do Desterro da Bahia e finalizando, apresenta as memórias da Província franciscana após a sua fundação.

Autor considerado o principal cronista franciscano brasileiro, foi quem mais enfatizou em seus escritos a primazia da ação franciscana no Brasil Colonial. Frei Jaboatão é e um dos escritores brasileiros do século XVIII a possuir maior número de publicações. Não se encontra um trabalho que ofereça uma relação completa de seus escritos, muitos dos quais, segundo José Antonio Gonsalves de Mello Neto, ainda não haviam sido descritos pelos seus biógrafos. Embora seja referência obrigatória em todas as obras sobre os franciscanos no Brasil Colonial, excetuando as de Venâncio Willeke ${ }^{18}$, são raros os trabalhos que oferecem maiores informações sobre a vida e as obras do autor.

Foram muitos os seus escritos, contudo, a obra que acabamos de apresentar registrou todas as atividades franciscanas no Brasil Colonial, e não obstante se trate de defesa contumaz da primazia da Ordem franciscana em relação às demais Ordens religiosas que missionaram no Brasil durante o Período Colonial, constitui uma primorosa produção, pesquisada e documentada, em que o autor se baseia na literatura brasileira e lusitana, bem como em fontes manuscritas dos arquivos públicos e religiosos de Pernambuco, Bahia, Paraíba e Sergipe. Segundo José Antonio Gonsalves de Mello Neto, apesar de apresentar deficiência na forma de identificação das fontes, Jaboatão não foi apenas um compilador de informações recolhidas em fontes bibliográficas, trabalhou ativamente com esse material, tendo também consultado livros de tombo dos mosteiros em Olinda e na Bahia, da Câmara Municipal de Salvador, o Livro de Acórdãos da Misericórdia de Olinda, os Arquivos dos Conventos Franciscanos da Paraíba e de Ipojuca, além de fontes orais que retratam, não só a história da Ordem franciscana no Brasil, mas 
também oferece aos historiadores informações para a compreensão das relações que se estabeleciam na sociedade brasileira durante o Período Colonial.

Importante observar a atualidade da preocupação do autor em relação às fontes e à escrita da história. Jaboatão a manifesta em várias passagens e no "antilóquio" de Orbe Seráfico Brasílico quando expõe:

[...] e he de ser história esta, que há de comprehender não só o passado, também o presente, o moderno e o antigo. E se qualquer destas partes só per si, e separada, causara notáveis, e evidentes perigos ainda aos escritores mais destros e versados; porque no antigo por falta de noticias he perigoso o exame, e no moderno pelos respeitos, muy arriscada a expressão; quanto mais nesta, que se há de compor destes dous tempos, e tão encontrados. Propomos porém, pela verdade, que professamos, de não faltar com o louvor a quem o merecer, nem menos com a crítica aonde for necessária; mas com tão justa, christã, e religiosa medida, que neste modo de expressão não seremos predominados de excesso algum exorbitante, nem de paixão para a critica, nem de affecto para o louvor.[sic]

Essas palavras expressam questões sobre a escrita da história incomuns para a época, como: objetividade, imparcialidade, contradição e totalidade.

Quiçá, seja por isso que a Jaboatão foi dado o título de historiador por intelectuais que conheceram sua obra. Gonsalves de Mello Neto, no prefácio de Novo Orbe Seráfico, assinala o reconhecimento de Jaboatão como historiador por renomados autores como Capistrano de Abreu, para quem "Jaboatão é melhor do que se supõe".

Porém, o cuidado do autor, ao apresentar o problema, antecipa a questão conflitante que existia entre as Ordens presentes no Brasil derivado do não reconhecimento da primazia dos franciscanos no campo missionário evangelizador. Foi em decorrência da ausência de sua alusão pela literatura existente e a defesa da primazia dos frades na evangelização do Brasil, que a obra foi elaborada. Esse foi, sem dúvida, o objetivo da obra. O zelo que o autor já possuía em relação ao tratamento de fontes documentais, o esforço de análise e fundamentação dos fatos evidencia o caráter combatente da mesma. Ele procurou, por meio da documentação de sua obra, não deixar espaço para dúvidas quanto a essa precedência.

Não obstante, o valor desse traço historiográfico presente na obra do autor e, que seja essa uma característica surpreendente em se tratando de uma Crônica setecentista, para os pesquisadores, assegura-se que sua relevância está muito mais nas informações e fontes documentais que compila e propicia do que em sua tentativa de rigor. Independentemente da apologética ou do rigorismo que contenha a obra, Jaboatão é, e sempre será o clássico fundamental para a história dos franciscanos no Brasil. Espera-se que, a partir de uma melhor divulgação desse rico manancial histórico, ele também passe a ser contemplado por historiadores de outros campos, incluindo, muito especialmente, os de história do Brasil.

Embora existam na literatura brasileira referências a outras obras escritas por franciscanos do Período Colonial ${ }^{19}$, que devem ser apreciadas pelos historiadores, "Novo Orbe Seráfico", de Frei Jaboatão, fecha um ciclo das Crônicas específicas sobre a história da Ordem franciscana no Brasil que só ressurgiram depois de um longo período. E todas, sem exceção e de forma obrigatória, a utilizaram como fundamento. Essas obras serão apresentadas no segundo artigo desta série que se intitulará: Fontes Franciscanas: Historiografia Franciscana Brasileira que abordará as produções específicas da historiografia franciscana brasileira. 


\section{Bibliografia}

APOLINÁRIO, Da Conceição. Epítome da Província Franciscana da Imaculada Conceição no Brasil. Lisboa, 1730.

D’ABBEVILlE, Cláudio. História da Missão dos Padres Capuchinhos na Ilha do Maranhão. São Paulo: Siciliano, 2002.

D’EVREUX, Yves. Viagem ao Norte do Brasil. Paris. Ferdinand Denis, 1864.

ILHA, Frei Manuel da. Narrativa da Custódia de Santo Antonio do Brasil. Texto bilíngüe. Trad. Frei Idelfonso Silveira. Petrópolis: Vozes, 1975.

JABOATÃO, Antonio de Santa Maria. Novo Orbe Seráfico Brasílico ou Crônica dos Frades Menores do Brasil. edição fac-símile. Lisboa, 1761, reeditado com nota prévia José Antônio Gonsalves de Melo Neto. Assembléia Legislativa do estado do Pernambuco. Recife, 1979. 1v.

Antonio de Santa Maria. Novo Orbe Seráfico Brasílico ou Crônica dos Frades Menores do Brasil. edição fac-símile. Lisboa, 1761, reeditado com nota prévia José Antônio Gonsalves de Melo Neto. Assembléia Legislativa do estado do Pernambuco. Recife, 1980. 1v.

Antonio de Santa Maria. Novo Orbe Seráfico Brasílico ou Crônica dos Frades Menores do Brasil. edição fac-símile. 1859, 1861, 1862. reeditado com nota prévia de Antonio Carlos de Oliveira. Reeditado pela Assembléia Legislativa do estado do Pernambuco. Recife, 1980. 3vs.

SANGENIS, Luiz Fernando. Gênese do Pensamento Único em educação: franciscanismo e jesuitismo na história da educação Brasileira. Petrópolis: Vozes, 2006.

WILLEKE, Venâncio (OFM). Frei Antonio de Santa Maria Jaboatão, O.F.M. Revista de História, v. 46, n. 93, p.47-67, 1973.

Notas:

\footnotetext{
${ }^{1}$ Mestre em educação pela Universidade Estadual de Maringá - UEM, Doutora em educação pela Universidade Estadual de Campinas - UNICAMP, Pós-doutoranda na Universidade Estadual de Campinas UNICAMP. Membro do Grupo de Pesquisa História, Sociedade e Educação no Brasil -HISTEDBR.

${ }^{2}$ Revisão bibliográfica elaborada para a consecução da tese de doutorado intitulada: A experiência Educativa da Ordem Franciscana: Aplicação na América e sua Influência no Brasil Colonial, defendida na UNICAMP em fevereiro de 2010 sob a orientação de Dermeval Saviani, foi considerada por Frei Sandro da Costa, professor de história dos franciscanos no Brasil e atual diretor do Instituto Teológico Franciscano do Brasil, situado em de Petrópolis, a mais completa revisão da categoria elaborada até o momento.

${ }^{3}$ IGLESIAS, Tania Conceição. A Experiência Educativa da Ordem Franciscana: aplicação na América e sua influência no Brasil Colonial. Campinas, 2010. Tese (Doutorado em História e Filosofia da Educação) Universidade Estadual de Campinas (UNICAMP), Fevereiro de 2010.

${ }^{4}$ Frei Ildefonso Silveira (1922-2002) foi membro da Ordem dos Frades Menores (OFM), professor de História Eclesiástica, exerceu várias funções na Ordem franciscana do Brasil. Pesquisador da história e da espiritualidade franciscanas traduziu, em linguagem acessível, as fontes e a história franciscana. Coordenou a edição do volume "São Francisco de Assis - Escritos e biografias - Crônicas e outros testemunhos do primeiro século franciscano”, pela Editora Vozes, em 1981. Foram muitos os seus artigos e livros, e o último, dedicado à análise histórica de documentos franciscanos, foi entregue à Editora Vozes no final de 2001.
}

Revista HISTEDBR On-line, Campinas, n.41, p. 125-135, mar2011 - ISSN: 1676-2584 


\begin{abstract}
${ }^{5}$ Trata-se de conflitos entre os jesuítas e os franciscanos pela posse das Missões na Paraíba para as quais o Rei Felipe II havia designado a ordem franciscana, o que acabou por provocar a expulsão dos jesuítas de tais Missões.

${ }^{6}$ Refere-se a frades franciscanos que estiveram no Brasil antes da fundação oficial da Custódia em 1584.

7 Frei Pedro Palácios, o mais célebre missionário franciscano no Brasil, desenvolveu suas atividades missionárias na Bahia e no Espírito Santo concomitantemente aos jesuítas. De origem espanhola, frei Pedro Palácio é lembrado por cronistas, tanto da ordem franciscana como da jesuítica.

${ }^{8}$ Vicente Rodrigues Palha nasceu na Bahia por volta de 1564. Lá, fez seus primeiros estudos, completandoos em Portugal onde se formou em Teologia e Cânones pela Universidade de Coimbra e retornou ao Brasil. Entrou para a ordem franciscana em 1599, quando adotou o nome de Frei Vicente do Salvador. Missionou na Paraíba, residiu em Pernambuco e cooperou na fundação da casa franciscana do Rio de Janeiro, em 1607, que foi seu primeiro prelado. Retornou a Pernambuco, onde Ministrou um curso de artes no Convento da ordem em Olinda. Regressando à Bahia, foi eleito guardião da ordem e custódio dos franciscanos entre 1612 e 1614, período em que teria escrito "Crônica da Custódia do Brasil". Foi também eleito Custódio da Custódia de Santo Antonio do Brasil. Em 1624, foi capturado e aprisionado por quatro meses pelos holandeses durante a invasão da Bahia. Em 1627, finalizou sua obra sobre a história do Brasil. Após haver estado em Portugal por volta de 1618-19, regressou à Bahia, onde permaneceu até falecer

${ }^{9}$ Dom Adriano Mandarino Hypólito nasceu em Aracaju em 18 de janeiro de 1918. Membro da Ordem dos Frades Menores Franciscanos, exerceu importantes funções eclesiásticas. Foi ordenado padre em Salvador no dia 18 de outubro de 1942, recebeu a ordenação episcopal no dia 17 de fevereiro de 1963 também em Salvador onde foi Bispo Auxiliar (1963-1966). Além disso, foi Padre Conciliar do Vaticano II (1963-1965), Delegado do Sínodo Romano (1977), Delegado à terceira Conferência Geral do Episcopado Latino Americano em Puebla (1979), Secretário da Regional Leste I da CNBB e Bispo Diocesano de Nova Iguaçu (1966-1994). Renunciou às funções Episcopais em novembro de 1994 e faleceu em 1996
\end{abstract}

${ }^{10}$ César Augusto Marques (1826-1900), que nasceu no Maranhão, cursou faculdade de Medicina na Bahia. Exerceu várias atividades, dentre as quais a de médico, de professor, destacando-se como escritor. Suas atividades literárias começaram ainda no tempo de estudante. Traduziu e escreveu várias obras, tais como: a importante obra sobre o Maranhão colonial, do capuchinho Yves d'Evreux; Provas da existência do outro mundo, fundadas sobre a natureza, história, filosofia e religião, publicada em Salvador, em 1852; Conquistas da Religião Cristã, de M.V. Robert, traduzido do francês, publicada em Salvador, em 1852; a obra A Meus Filhos ou os Frutos do bom exemplo, de Prospero Blanchard, do original francês, lançada no Maranhão, em 1869. César Marques publicou ainda o Almanaque Histórico de Lembranças Brasileiras, em 1861; Breve Memória sobre a vacina no Maranhão, em 1862; Apontamentos para o Dicionário histórico, geográfico, topográfico e estatístico da Província do maranhão e Dicionário Histórico-Geográfico e Estatístico da Província do Espírito Santo, em 1870. Foi membro das seguintes instituições: Sociedade Auxiliadora da Indústria Nacional do Rio de Janeiro; Sociedade de Ciências Médicas de Lisboa, em 1857; Ateneu Maranhense, em 1860; Ateneu Paraense, em 1861; Sociedade de Beneficência Luso-Maranhense, em 1861; Instituto Histórico e Geográfico Rio-Grandense, em 1863; Instituto Histórico e Geográfico da Bahia, em 1863; Imperial Academia de Medicina do Rio de Janeiro, em 1864; Instituto Histórico e Etnográfico do Brasil, em 1865; Instituto Literário Maranhense, em 1865; Conservatório Dramático da Bahia, em 1866; Instituto Arqueológico e Geográfico Alagoano e União Católica do Rio de Janeiro, em 1870. Foi sócio da Real Sociedade Humanitária do Porto, em 1858, e do Instituto Arqueológico e Geográfico Pernambucano, em 1863. César Marques é patrono da cadeira n.35 da Academia Maranhense de Letras, da n.07 da Academia Caxiense de Letras e de uma do Instituto Histórico e Geográfico do Maranhão. Foi agraciado com as comendas da Ordem Militar de N.S. Jesus Cristo de Portugal; Cavaleiro da Imperial Ordem da Rosa do Brasil e Oficial da Academia da França.

${ }^{11}$ Claude d'Abbeville nasceu em Lyon na França. Não se tem certeza sobre sua data de nascimento e morte. O que se encontra é a referência ao seu ano de morte entre 1616 e 1632. Participou da missão capuchinha no Maranhão em 1612, onde pretendia consolidar a conquista francesa no estabelecimento colonial comandado por Daniel de la Touche. Como a missão fracassou devido às investidas portuguesas, Frei Claude regressou à França quatro meses depois. .

${ }^{12}$ D'EVREUX, Yves (1570-1620?) era o superior do grupo franciscano capuchinho que chegou ao Maranhão em 1612 na expedição de Daniel de La Touche, durante a segunda ocupação francesa para a conquista daquela região. Retornou à França em 1615. Publicou importante obra onde relata os acontecimentos do 
período em que viveu no Maranhão, mas a mesma foi proibida de circular por questões diplomáticas entre os reinos da Espanha e da França em face do casamento, em 1615, do rei Luiz XIII da França com a princesa Anne d'Autriche, filha do Rei da Espanha, então soberano de Portugal e de suas colônias. A corte francesa não teve, a partir daí, grande interesse numa colônia francesa no território Brasileiro. François de Rasilly, militar participante da expedição em que veio Frei Yves, conservou o livro. Ele salvou as partes que restaram depois de uma censura de mãos desconhecidas na oficina do impressor em Paris. A obra foi encontrada e publicada por Ferdinand Denis em 1864 com o título: Voyage dans le nord du Brésil.

13 Viagem ao norte do Brasil, obra escrita durante os anos de 1613 a 1614 pelo Padre Yves D'evreux, religioso capuchinho, publicada em exemplar único conservado na Biblioteca imperial de Paris, com introdução e notas de Ferdinand Denis, foi traduzida e publicada no Brasil por Cezar Augusto Marques, no Maranhão em 1874 e reeditada no Rio de Janeiro em 1929.

${ }^{14}$ Os dois Freis Capuchinhos participaram da mesma missão francesa católica no Maranhão em 1612.

${ }^{15}$ Frei Apolinário da Conceição, irmão leigo, nasceu em Lisboa em 1692, mudou-se para o Brasil com a família e tornou-se franciscano em 1711, em São Paulo, no Convento de São Francisco. Apesar de não ter estudado na ordem e de não se ter notícia do local onde fez seus estudos até ingressar no noviciado, tinha interesse por história e, incentivado por Frei Fernando de Santo Antonio, passou a se dedicar à pesquisa. Percorreu Conventos e bibliotecas na Espanha, Itália e França em busca de documentos históricos, compilando-os e publicando-os, tornando-se cronista e escritor oficial da ordem franciscana, cujos trabalhos constituem uma das principais fontes sobre a história da ordem no Período Colonial. Em 1724, foi enviado a Lisboa como procurador da ordem, tendo retornado em 1728 para o Convento de Santo Antonio no Brasil. Voltou a Portugal em 1729, onde elaborou "Epítome da Província Franciscana da Imaculada Conceição no Brasil”, concluída em 1730. Em 1740, no Capítulo Geral celebrado em Valladolid, recebeu o título de cronista da sua Província. Morreu no Brasil em 1760.

${ }^{16}$ SANGENIS, Luiz Fernando. Gênese do Pensamento Único em educação: franciscanismo e jesuitismo na história da educação Brasileira. Petrópolis: Vozes, 2006. O autor chama a atenção para a insistente ênfase dos autores e cronistas franciscanos sobre a questão da primazia da ordem franciscana no Brasil, como uma questão que, desde o Período Colonial, demonstra os conflitos gerados quanto à aceitação da legitimidade dessa atuação.

${ }^{17}$ José Antonio Gonsalves de Mello (1916-2002), advogado, jornalista e ilustre historiador pernambucano, nasceu em Recife. Primo de Gilberto Freire, iniciou suas atividades literárias, auxiliando nas pesquisas históricas para o livro Casa Grande \& Senzala. Teve várias obras publicadas, exerceu diversos cargos e colecionou muitos títulos no meio literário, entre eles, a cadeira $\mathrm{n}^{\circ} 37$ da Academia Portuguesa História de Lisboa. Presidente do Instituto Arqueológico, Histórico e Geográfico do Pernambuco, por ocasião da reedição pela Assembléia Legislativa de Pernambuco do Novo Orbe Seráfico Brasílico em 1980, foi prefaciador dessa edição. Segundo ele, esses textos se encontram na "Coleção da Miscelânea" da Biblioteca da Universidade de Coimbra.

18 Consultar: WILLEKE, Venâncio (OFM). Frei Antonio de Santa Maria Jaboatão, O.F.M. Revista de História, v. 46, n. 93, p.47-67, 1973. Willeke foi quem mais se dedicou ao estudo sobre Frei Jaboatão no Brasil.

${ }^{19}$ Entre essas obras, quer se destacar as seguintes: a de frei Cristóvão de Lisboa, escrita entre 1635 e 1641 , intitulada "História dos Animais e Arvores do Maranhão", que foi publicada por Jaime Walter, em Lisboa, em 1967; a de Frei Domingos Loreto Couto, que, na verdade, compõe duas obras - "Desagravos do Brasil e Glórias de Pernambuco" (1757) -, tendo sido valorizada, em princípios do século XX, por Capistrano de Abreu e permanecido inédita até 1902; a do Frei Mariano Veloso, Flora Fluminensis, publicada entre 1825 e 1827; a do Frei Martinho de Nantes, que, além de escrever "Relação de uma missão no rio São Francisco" Relação sucinta e sincera da missão do padre Martinho de Nantes, pregador capuchinho, missionário apostólico no Brasil, de 1687, publicada em 1707 na Bahia, ensinou a língua Kariri ao Frei capuchinho francês, Bernard de Nantes, que, por sua vez, elaborou, em 1709, uma gramática nessa língua intitulada " $O$ Catecismo índico na língua Kariri"; e a do Frei Yves d'Evreux, "Viagem ao Norte do Brasil", publicada em Paris em 1615 e traduzida por César Augusto Marques em 1874.

Recebido em 19/11/2010

Aprovado em 25/1/2011 